\title{
Aircraft Loss of Control Causal Factors and Mitigation Challenges
}

\author{
Steven R. Jacobson ${ }^{*}$ \\ NASA Dryden Flight Research Center, Edwards, California, 93523
}

\begin{abstract}
Loss of control is the leading cause of jet fatalities worldwide. Aside from their frequency of occurrence, accidents resulting from loss of aircraft control seize the public's attention by yielding a large number of fatalities in a single event. In response to the rising threat to aviation safety, the NASA Aviation Safety Program has conducted a study of the loss of control problem. This study gathered four types of information pertaining to loss of control accidents: (1) statistical data; (2) individual accident reports that cite loss of control as a contributing factor; (3) previous meta-analyses of loss of control accidents; and (4) inputs solicited from aircraft manufacturers, air carriers, researchers, and other industry stakeholders. Using these information resources, the study team identified the causal factors that were cited in the greatest number of loss of control accidents, and which were emphasized most by industry stakeholders. This report describes the study approach, the key causal factors for aircraft loss of control, and recommended mitigation strategies to make near-term impacts, mid-term impacts, and Next Generation Air Transportation System impacts on the loss of control accident statistics.
\end{abstract}

\section{Nomenclature}

$\begin{array}{ll}\text { ALPA } & \text { Air Line Pilots Association } \\ \text { AvSafe } & \text { NASA Aviation Safety Program } \\ \text { ASRS } & \text { Aviation Safety Reporting System } \\ \text { CAST } & \text { Commercial Aviation Safety Team } \\ \text { FAA } & \text { Federal Aviation Administration } \\ \text { IRAC } & \text { Integrated Resilient Aircraft Control project } \\ \text { JSAT } & \text { CAST Joint Safety Analysis Team } \\ \text { LOC } & \text { loss of control } \\ \text { LOC-I } & \text { loss of control - in flight } \\ \text { MGW } & \text { maximum gross weight } \\ \text { NASA } & \text { National Aeronautics and Space Administration } \\ \text { NextGen } & \text { Next Generation Air Transportation System } \\ \text { NTSB } & \text { National Transportation Safety Board } \\ \text { PIO } & \text { pilot-induced oscillation } \\ \text { URT } & \text { upset recovery training } \\ \text { URTA } & \text { Upset Recovery Training Aid }\end{array}$

\section{Introduction}

Over the last decade, loss of control has become the leading cause of commercial jet fatal accidents worldwide. "Well over half of the loss of control accidents included at least one fatality (80 percent in Part 121), and roughly half of all aviation fatalities ... occurred in conjunction with loss of control. Loss of control events are rarely considered incidents, due to the level of aircraft damage and injury that is likely to occur."

Loss of control accidents attract attention not only as a result of their status as the most common type of accident, but also because of the disturbing number of fatalities they produce. The crash of a Colgan Air regional

${ }^{*}$ Chief, Controls and Dynamics Branch, P.O. Box 273, MS 4840D, e-mail: Steve.Jacobson@nasa.gov, AIAA Senior Member. 
transport in 2009 resulted in widespread media attention and in proposed legislation in both houses of the United States Congress.

In response to this increasing threat to aviation safety, the National Aeronautics and Space Administration (NASA) Aeronautics Research Mission Directorate (ARMD) Aviation Safety Program (AvSafe) office chartered a study of the loss of control problem. This paper reviews the primary causal factors for the loss of control hazard as determined by the NASA LOC study team and discusses briefly the technical challenges identified that affect nearterm, mid-term and Next Generation Air Transportation System (NextGen) approaches to addressing the loss of control problem.

The study team adopted the following definition of loss of control, from the 2000 Commercial Aviation Safety Team (CAST) Joint Safety Analysis Team (JSAT report on loss of control.

Loss of control includes significant, unintended departure of the aircraft from controlled flight, the operational flight envelope, or usual flight attitudes, including ground events. "Significant" implies an event that results in an accident or incident. This definition excluded catastrophic explosions, CFIT, runway collisions, complete loss of thrust that did not involve loss of control, and any other accident scenarios in which the crew retained control. This does include loss of control due to aircraft design, aircraft malfunction, human performance, and other causes. ${ }^{2}$

\section{NASA Loss of Control Study Team and Approach}

The NASA study team consisted of seven NASA engineers and scientists from four NASA research centers: the NASA Langley Research Center (LaRC), Hampton, Virginia, USA; the NASA Ames Research Center (ARC), Moffett Field, California, USA; the NASA Glenn Research Center (GRC), Cleveland, Ohio, USA; and the NASA Dryden Flight Research Center (DFRC), Edwards, California, USA. All team members have strong backgrounds in the NASA Aviation Safety Program with skills that include flight control, flight dynamics, loss of control, flight research, aircraft icing, human factors, flight training, pilot-human automation, human performance, and human error.

The study team was chartered with identifying the key causal factors related to aircraft loss of control, making recommendations on candidate mitigations, and identifying supporting research for the mitigations. The time frame for the study was approximately three months, with one additional month for writing reports. In order to accomplish the objectives within such a span of time, the study team adopted the following approach.

\section{A. Loss of Control Study Activities}

The NASA study team:

1) Identified a list of candidate causal factors for consideration

2) Developed a list of stakeholders representing government entities such as NASA, the Federal Aviation Administration (FAA), the National Transportation Safety Board (NTSB), airframe manufacturers, airlines, pilot unions and training providers

3) Interviewed subject matter experts who represent stakeholders to gain an understanding of the causal factors behind loss of control mishaps, and potential mitigations

4) Reviewed previous work that addressed the loss of control hazard, such as that performed by the CAST JSAT and the CAST Joint Safety Implementation Team (JSIT), and that presented in technical papers, NASA work, the Upset Recovery Training Aid (URTA), et cetera

5) Reviewed statistical summary reports for loss of control accidents and incidents

6) Reviewed selected loss of control accident reports

7) Analyzed the data and interview notes to arrive at a list of candidate mitigations for loss of control events and potential research topics that could help support implementation of same

8) Prioritized causal factors, and identified candidate mitigations and supporting research topics

9) Prioritized mitigations and research

10) Documented findings and recommendations

The team was directed to consider loss of control mitigations from both a short-term and long-term perspective with the intent of identifying mitigations that would affect the fatal accident rate as soon as possible but also would address the evolving state of commercial aviation, such as NextGen airspace concepts and advanced aircraft systems, as they are introduced. 


\section{B. Candidate Causal Factors}

The study team developed a preliminary list of causal factors that contribute to loss of control. This list was compiled through interviews, reviews of accident reports and team analysis of available data. Causal factors in the list were segregated into three categories: (1) pilot- or human-induced; (2) environmentally-induced; and (3) systems-induced. The following list does not order the causal factors by frequency of occurrence or importance.

Pilot- or human-induced:

1) Improper training

2) Poor energy management

3) Changing pilot skill base

4) Spatial disorientation

5) Poor pilot awareness

6) Distraction

7) Automation confusion or mode confusion

8) Automation and human factors

9) Improper procedure

10) System integration issues (complexity, interdependencies and lack of standard interfaces)

11) Pilot actions leading to destabilized approaches

12) Faulty loading or shifting of cargo

13) Incompetence

Environmentally-induced

1) Weather (turbulence, icing, adverse winds, wind shear)

2) Wake vortices

3) Hail leading to loss of control (engine performance)

4) Visibility degrading to instrument meteorological conditions (IMC) for general aviation (GA) aircraft, that is, visual flight rules (VFR) flight into IMC

5) Foreign object damage (hail, bird strike, volcanic ash)

Systems-induced

1) Poor design

2) Poor energy management (systems-induced)

3) Propulsion related (asymmetric thrust, energy management)

4) Erroneous sensor data

5) Air traffic operations leading to destabilized approaches

6) Loss of control power, authority, or effectiveness

7) Aircraft system failures (non-propulsion and propulsion)

8) Faults or failures or damage of or to any or all of the aircraft control effectors

9) Pilot-induced oscillation (PIO)

\section{Background on Loss of Control Accident Statistics}

A number of previous studies were reviewed as part of this effort. Two of those presented data in a manner of particular relevance to this study: the 2009 Boeing Statistical Summary of Commercial Jet Airplane Accidents and an analysis of accident data by the NASA systems analysis group on behalf of the Integrated Resilient Aircraft Control (IRAC) project.

\section{A. The Boeing Annual Statistical Summary of Airplane Accidents}

The annual Boeing Statistical Summary of Commercial Jet Airplane Accidents3 is often the motivator for aviation safety research. A chart from the 2009 report is included as Fig. 1 below. 


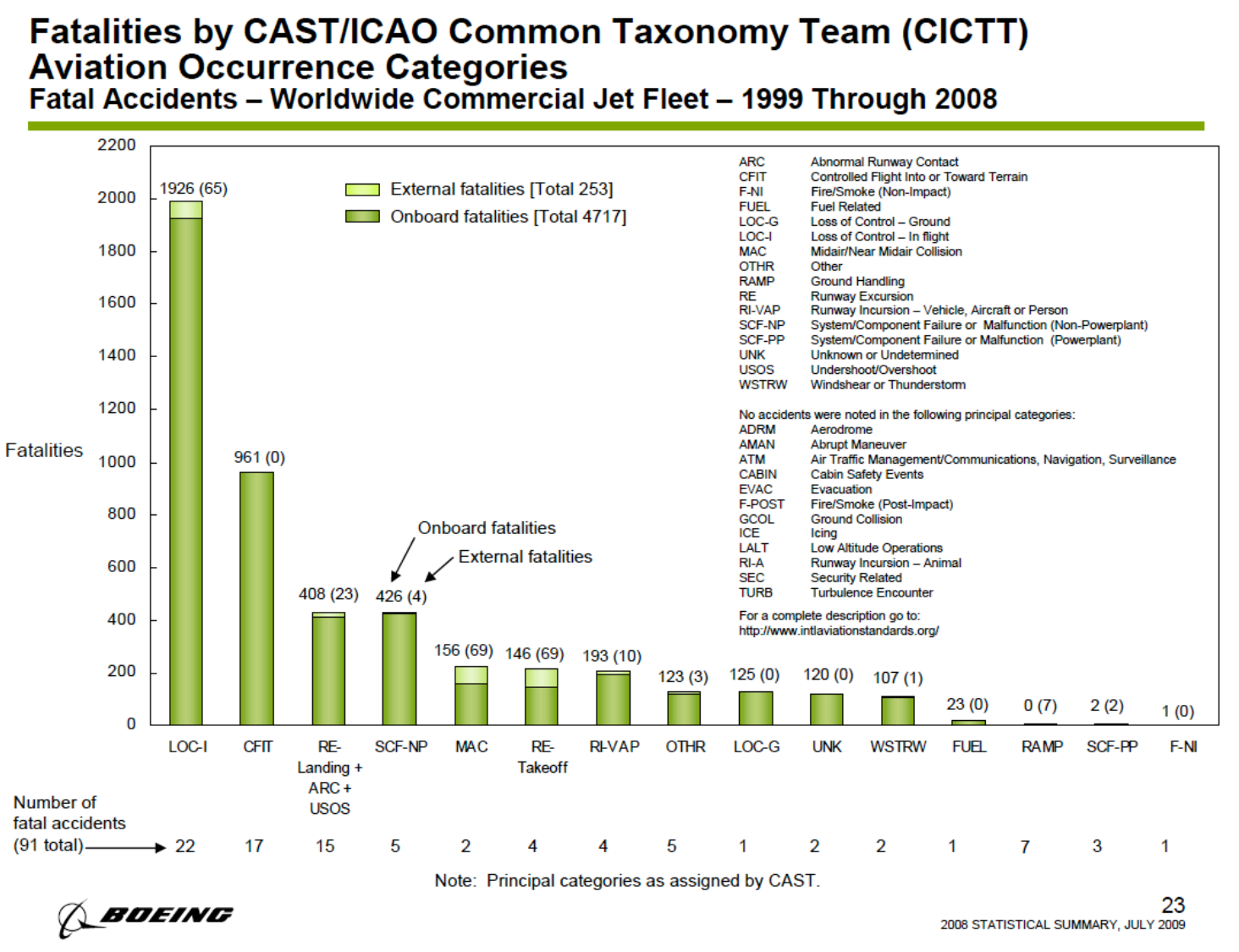

Figure 1. Worldwide fatal accidents by occurrence category. ${ }^{3}$

A few important considerations about the chart shown in Fig. 1 are that it:

1) Includes statistics from Part 121 aircraft weighing more than $60,000 \mathrm{lb}$ maximum gross weight (MGW)

2) Does not include statistics from aircraft manufactured in the Commonwealth of Independent States or USSR

3) Does not include statistics from aircraft used in military service

The data presented in Fig. 1 do not include recent accidents such as the Colgan Air crash in Buffalo, New York, USA, and the crash of Air France Flight 447 off of the coast of Africa. Preliminary indications are that loss of control occurred in both of these accidents.

Loss of control in flight (LOC-I) is the most significant cause of commercial aviation fatalities worldwide. Insight into root causes is gained by examining at the details of each accident, thus, the study team reviewed accident summaries for each of the 22 fatal accidents noted in the LOC-I category with the goals of understanding the nature of these accidents and identifying the underlying causal and contributing factors. Tables 1 through 4 present data describing worldwide in-flight loss of control accidents.

Table 1. LOC-I accidents that occurred in each causal factor category, 1999-2008.

\begin{tabular}{lcc}
\hline Causal factor category & $\begin{array}{c}\text { Number of LOC-I accidents as } \\
\text { primary causal factor }\end{array}$ & $\begin{array}{c}\text { Number of LOC-I accidents as } \\
\text { contributing causal factor }\end{array}$ \\
\hline Pilot- or human-induced & 16 & 22 \\
Environmentally-induced & 4 & 5 \\
Systems-induced & 2 & 7 \\
\hline \hline
\end{tabular}


Table 2. Causal factors contributing to LOC-I commercial aircraft fatal accidents, 1999-2008.

\begin{tabular}{lc}
\hline \multicolumn{1}{c}{ Causal factor } & $\begin{array}{c}\text { Number of fatal accidents } \\
\text { with causal factor }\end{array}$ \\
\hline \multicolumn{2}{c}{ Pilot- or human-induced } \\
Improper procedure & 10 \\
Spatial disorientation & 6 \\
Poor energy management & 6 \\
Distraction & 5 \\
Improper training & 5 \\
Poor design & 2 \\
& \\
Weather Environmentally-induced & 3 \\
Icing & 2 \\
Wake vortex & 1 \\
Aircraft systems failures & 5 \\
Poor design & 2 \\
\hline \hline
\end{tabular}

Table 3. Regions in which fatal LOC-I commercial aircraft fatal accidents occurred, 1999-2008.

\begin{tabular}{lc}
\hline \multicolumn{1}{c}{ Region } & Number of fatal accidents \\
\hline Asia (except China) & 6 \\
Europe & 5 \\
Africa & 4 \\
Latin America/Caribbean & 3 \\
Commonwealth of & 2 \\
Independent States & \\
Middle East & 1 \\
USA and Canada & 1 \\
China & 0 \\
\hline \hline
\end{tabular}


Table 4. Phase of flight in which fatal loss of control accidents occurred, 1999-2008.

\begin{tabular}{lc}
\hline \hline \multicolumn{1}{c}{ Phase of flight } & Number of fatal accidents \\
\hline Climb & 6 \\
Takeoff & 5 \\
Final approach & 3 \\
Initial climb & 2 \\
Cruise & 2 \\
Initial approach & 2 \\
Landing & 2 \\
\hline \hline
\end{tabular}

Some important generalizations, presented as the list of findings below, can be derived from the data presented in tables 1 through 4.

Finding 1: of the 22 accidents in the LOC-I occurrence category, the leading causal factors fall within pilot- or human-induced category.

Finding 2: for large aircraft, the majority (95 percent) of recent LOC-I fatal accidents occur outside of the United States and Canada.

Finding 3: the majority ( 81 percent) of recent LOC-I accidents occur during flight phases in which the aircraft is relatively close to the ground, leaving little time for corrective action, and under circumstances that are unforgiving of errors.

Finding 4: flight crew deviation from prescribed procedure is a significant factor in loss of control accidents.

Finding 5: spatial disorientation is a problem, but it occurs primarily outside of the United States.

Finding 6: poor energy management (for example, the aerodynamic stall) is a significant factor in loss of control accidents.

Accident reports in other occurrence categories were examined for relevance to loss of control. None of the accidents in System/Component Failure-Propulsion could be categorized as loss of control accidents. Several of the accidents in the System/Component Failure (Non-Propulsion) occurred in flight, but there was insufficient evidence to suggest that they could be strictly categorized as LOC-I.

\section{B. NASA Systems Analysis Study on Loss of Control Accidents and Incidents}

While the accidents cited in the Boeing annual report are good indicators for worldwide recent accident statistics involving larger aircraft, more data are needed to gain insight into causal factors for both incidents and accidents and for aircraft weighing less than $60,000 \mathrm{lb}$ MGW.

The IRAC project within the NASA Aviation Safety Program conducted a study of civil aviation accidents that occurred from 1988 through 2004, to identify loss of control events and causal factors. The study examined NTSB accident data, FAA incident data and NASA Aviation Safety Reporting System (ASRS) incident data for Part 121, Part 135, and Part 91 operations (commercial aviation, chartered operations, and general aviation) in order to identify causal factors related to aircraft loss of control for the complete range of civilian aircraft operations. The systems analysis results are documented in NASA/TM-2010-2162611 (Reveley, et al.). The study team used these results, data from accidents listed in the Boeing annual report, and stakeholder inputs, in order to gain insight into loss of control causal factors. Table 51 shows loss of control events for civil aviation occurring in the United States from 1988 through 2004. The total for loss of control accidents is 0.1 per million flight hours for Part 121 operations; however, the picture is grimmer for Part 135 and general aviation operations. 
Table 5. Summary of loss of control events by operation category in the US, 1988-2004. ${ }^{1}$

\begin{tabular}{|c|c|c|c|c|c|}
\hline \multirow[b]{2}{*}{ Type of events } & \multicolumn{5}{|c|}{ Operation Category } \\
\hline & Part 121 & $\begin{array}{l}\text { Scheduled } \\
\text { Part } 135\end{array}$ & $\begin{array}{c}\text { Non- } \\
\text { Scheduled } \\
\text { Part } 135 \\
\end{array}$ & Part 91 & $\begin{array}{c}\text { Part 91, 135, } \\
\& 121 \\
\text { Combined } \\
\end{array}$ \\
\hline $\begin{array}{l}\text { Total Flight } \\
\text { Hours }\end{array}$ & $251,751,143$ & $25,353,146$ & $49,588,000$ & $441,207,000$ & $767,896,289$ \\
\hline Total Accidents & 630 & 217 & 1115 & 24473 & 26435 \\
\hline LOC Accidents & $\begin{array}{r}26 \\
\text { (4\% of Total } \\
\text { Accidents) }\end{array}$ & $\begin{array}{r}32 \\
\text { (15\% of Total } \\
\text { Accidents) }\end{array}$ & $\begin{array}{r}198 \\
\text { (18\% of Total } \\
\text { Accidents) }\end{array}$ & $\begin{array}{r}4961 \\
\text { (20\% of Total } \\
\text { Accidents) }\end{array}$ & $\begin{array}{r}5217 \\
(20 \% \text { of Total } \\
\text { Accidents })\end{array}$ \\
\hline $\begin{array}{l}\text { LOC Accidents } \\
\text { per million flight } \\
\text { hours }\end{array}$ & 0.10 & 1.26 & 4.03 & 11.24 & 6.79 \\
\hline Fatal Accidents & $\begin{array}{r}62 \\
\text { (10\% of total } \\
\text { accidents) }\end{array}$ & $\begin{array}{r}49 \\
\text { (23\% of total } \\
\text { accidents) }\end{array}$ & $\begin{array}{r}293 \\
\text { (26\% of Total } \\
\text { Accidents) }\end{array}$ & $\begin{array}{r}4815 \\
(20 \% \text { of Total } \\
\text { Accidents })\end{array}$ & $\begin{array}{r}5289 \\
(20 \% \text { of Total } \\
\text { Accidents })\end{array}$ \\
\hline $\begin{array}{l}\text { Fatal LOC } \\
\text { Accidents }\end{array}$ & $\begin{array}{r}21 \\
\text { (81\% of LOC } \\
\text { accidents) }\end{array}$ & $\begin{array}{r}19 \\
\text { (59\% of LOC } \\
\text { accidents) }\end{array}$ & $\begin{array}{r}128 \\
\text { (65\% of LOC } \\
\text { Accidents) }\end{array}$ & $\begin{array}{r}2635 \\
\text { (53\% of LOC } \\
\text { Accidents) }\end{array}$ & $\begin{array}{r}2803 \\
\text { (54\% of LOC } \\
\text { Accidents) }\end{array}$ \\
\hline Total Fatalities & 2165 & 328 & 698 & 9146 & 12337 \\
\hline $\begin{array}{l}\text { Fatalities in LOC } \\
\text { Accidents }\end{array}$ & $\begin{array}{r}1186 \\
(55 \%)\end{array}$ & $\begin{array}{r}161 \\
(49 \%)\end{array}$ & $\begin{array}{r}285 \\
(41 \%)\end{array}$ & $\begin{array}{r}5178 \\
(57 \%)\end{array}$ & $\begin{array}{r}6810 \\
(55 \%)\end{array}$ \\
\hline Total Incidents & 7808 & 2234 & 2201 & 29520 & 41,763 \\
\hline LOC Incidents & 38 & 5 & 8 & 81 & 132 \\
\hline $\begin{array}{l}\text { LOC Incidents } \\
\text { per million flight } \\
\text { hours }\end{array}$ & 0.151 & 0.197 & 0.161 & 0.18 & 0.17 \\
\hline
\end{tabular}

The summary shown in table 5 is one of few that provide a broad and cross-cutting view across operating categories. While the LOC accident rate is significantly less for Part 121 than for the other operation categories, the incident rates are very similar and the fatalities per LOC accident are significantly higher for Part 121 than for Part 91. The LOC study team gleaned some important findings from the Reveley report.

Finding 7: more than half of LOC-I events result in an accident and more than half of those accidents are fatal. Reveley, et al., expands further on this conclusion when considering the four operational categories:

In flight loss of control is a serious aviation problem. Well over half of the loss of control accidents included at least one fatality ( $80 \%$ in Part $121,64 \%$ in Part 135 and 53\% in Part 91.), and roughly half of all aviation fatalities in the studied time period occurred in conjunction with loss of control. Loss of control events are rarely considered incidents, due to the level of aircraft damage and injury that is likely to occur. 
In Part 121, loss of control was somewhat more likely to occur during approach and landing (as opposed to takeoff or en route), but during takeoff a loss of control was most likely to result in a fatality. In Part 135 flights, loss of control was most likely to occur during takeoff, although when control was lost during approach/landing 80 percent of the accidents resulted in fatalities. En route loss of control was both the most frequent and the most often fatal of the three phases in Part 91 flights.

In $31 \%$ of Part 121 loss of control accidents, the loss of control was secondary to a system/component failure/malfunction, compared with $8 \%-12 \%$ of the accidents in other flight operation categories. Twentythree percent of the Part 121 loss of control accidents were secondary to aircraft damage (most often due to fire), compared with $3 \%$ to $8 \%$ of the accidents in other flight operation categories. As a result, for roughly $35 \%$ of the loss of control accidents in Part 121, aircraft control was not possible (Determined by the NTSB), compared with $6 \%$ to $9 \%$ of the accidents in other flight operation categories. In flights other than Part 121, $25 \%$ to $40 \%$ of the loss of control was caused by inadequate airspeed leading to an inadvertent stall. Icing (both pre-flight and in-flight) and adverse winds were the primary cause of a large number of accidents. Other frequently cited causes for loss of control are inadequate pre-flight, improper planning or decisions, and flying in obscuration or at night. ${ }^{1}$

Finding 8: in approximately one third of Part 121 loss of control accidents, loss of control was due to a system component failure.

Finding 9: approximately 34 percent of all fatal Part 121 accidents are LOC accidents.

Finding 10: in approximately one third of Part 121 accidents, the NTSB determined control was not possible, although the meaning of this is not clear. For instance, did inadequate control authority exist due to damage or some other factor? Could the aircraft have been controllable with the aid of technology that is not currently available?

While the Boeing Annual Report and the Reveley report are statistical summaries that provide useful insight into accident causal factors, it is important to use caution with any accident summary or analysis. First, the timeframe for accident summaries can affect the results. Certain issues may not be apparent within short time frames (such as 10 years) whereas they are significant within longer time frames (such as 30 years). This could be due to systemic reduction in certain causal factors or the cyclic nature of some causal factors. Second, statistical summaries do not necessarily provide important details regarding the circumstances underlying the accident, largely because causal factors are often summarized within broad categories. The LOC study team obtained valuable information from the full accident reports that was not apparent in the summaries. Finally, the identification of all contributing causal factors for each accident, instead of the single primary cause, was found to be most appropriate for purposes of identifying mitigation strategies. Therefore, further accident analysis may be needed for the development of any mitigation or research strategy. The accident analyses conducted by Reveley, ${ }^{1} \mathrm{Smith}^{4}$ and Lambregts ${ }^{5}$ all provided insight into causal factors but used different approaches for certain aspects of the analyses.

\section{Mitigation Hierarchy, Classification, and Approaches}

A mitigation is an action taken to reduce the risk of exposure to a hazard. Based on System Safety Science, once a hazard is identified the priority for addressing the hazard should be:

1) Hazard elimination (intrinsic safety)

2) Hazard reduction

3) Hazard control

4) Damage reduction ${ }^{6}$

For aircraft loss of control, hazard elimination is a desirable but difficult-to-reach goal, given the nature of performance demands in atmospheric flight. Thus, research should focus on hazard reduction, hazard control, and damage reduction.

In practical applications involving aircraft systems a more specific priority model is used. ${ }^{7}$

1) Design/Eliminate: design to eliminate the hazard or to minimize risk (for example, the possibility of an electrical fire can be eliminated by using a pneumatic system or using redundancy in flight controls to lower the probability of occurrence of flight control failure due to an electrical fire).

2) Safety Devices: incorporate safety features or safety devices or both to minimize risk (for example, utilize safety lockout or use-inhibiting devices.)

3) Detect/Warn: incorporate warning or caution or detection devices to minimize risk (for example, utilize a flashing light with a sign to indicate the presence of a hazard). Detection and warning devices may aid in notifying the crew of a hazardous event as well as in providing guidance toward reducing the effects of a hazardous event. 
4) Procedures/Training: use special procedures, training, personal protective equipment, or a combination of any or all of these to minimize risk. Procedures and training may be applicable to avoiding a hazardous situation, detecting the onset of a hazardous event, and training to contain or reduce the effects of a hazardous event.

5) Placards: use placards to minimize risk. Due to their lack of effectiveness, placards are not discussed in this report.

The preferred methods incorporate elimination of or protection from the hazard through avoidance of the hazard, design, or the use of safety devices. These are followed by the use of detection and warning systems to advise that a hazard is imminent or occurring. Procedures and training are important for both prevention of and recovery from a hazard, but are near the bottom of the list of preferred approaches because they rely on human operators to remember the training and use the proper procedures. As pointed out previously, deviation from proper procedure is a significant factor in loss of control accidents.

Achieving hazard elimination by developing technology and design changes for existing aircraft designs is expensive and is likely to take decades to affect loss of control accident statistics. This is true of all existing aircraft and will likely remain true for all aircraft flying through the year 2020. NextGen aircraft $(\mathrm{N}+2$ and later) may benefit from research that is performed related to aircraft and systems design; however, designing out the loss of control hazard while achieving some of the other goals associated with NextGen will be very difficult.

Incorporating safety features or devices that minimize risk, such as inhibitor devices, is more likely to have an impact on future aircraft. Retrofit-able avionics systems may be able to "buy" their way onto the airplane if they offer some additional performance or monetary benefit to the operators that will fly them.

A similar argument is made for warning or caution or detection devices. It may be possible to incorporate these mitigators with equipment that is required for aircraft to operate within the NextGen architecture; however, integration onto existing aircraft will not likely happen without a legislative or financial incentive.

While next-to-the-bottom-of-the-list for preferred mitigation approaches, procedures and training are likely to have the largest impact on the loss of control hazard in the near term. Any new technology that migrates into commercial aviation will have limited impact on loss of control accident statistics in the near term and will likely first be incorporated onto aircraft that already receive the best maintenance and are flown by the most experienced pilots.

On the other hand, research to support loss of control prevention and recovery training may be applied and may affect accident statistics in as little as a few years after completion of the research; however, there is a cost associated with training. The LOC training would need to "earn" its way into current training curricula. Training and procedures are often considered a stopgap measure; however, the technology infusion gap in commercial aviation can be measured in decades. For commercial aircraft operations, most loss of control accidents with fatalities occur outside of the United States and Canada on older aircraft that were purchased used from premium carriers. In the United States, Part 135 and Part 91 operations have the highest frequency of loss of control accidents and are the least likely group to be effected by technology improvements, for economic reasons. Research tasks that support improved training and procedures are the most important for a near-term impact on the loss of control statistics.

The topic of "technology insertion" should be a critical element of any LOC mitigation strategy. While the primary impact of certain technologies may be long-term, it is important to identify the areas in which they could be inserted as soon as possible, to accelerate technology readiness. For example, integrated aero-propulsive controls may progress from manual implementations to full automatic implementation as part of the maturation process. Also, while certain barriers to technology insertion exist, such as certification or cost, these barriers may be reduced through unexpected circumstances or the gradual implementation of technologies.

The aircraft loss of control problem results from numerous primary causal factors and contributing causal factors that may occur individually but quite often occur in combination. Loss of control usually occurs in an offnominal condition that may creep up gradually, but it can occur suddenly without warning. Typically, it is a surprise to the pilot. Loss of control occurs across all operational categories. Usually there is a chain of events that precedes a loss of control event and, unlike the controlled flight into terrain (CFIT) problem, for which the fatality rate has been drastically reduced by the required use of terrain alert warning systems (TAWS), ${ }^{8}$ there is no single unifying mitigation technology strategy that will address the majority of loss of control causal factors. Breaking the chain of events is an important approach in effective mitigation for aircraft loss of control. If the complex loss of control chain is broken at any link, the event is not likely to occur. ${ }^{9}$

In an effort to address breaking the chain of events in aircraft loss of control at multiple points, the LOC study team chose to classify the mitigations by the manner in which the mitigations would be applied to a loss of control event. The mitigation application categories are Avoid, Detect, and Recover. ${ }^{10}$ 
Avoid: avoidance is usually tied to the design of systems that eliminate the hazard and safety mitigations but may also include standard operating procedures and training to avoid loss of control scenarios. These mitigation strategies include:

1) Aircraft designs and system architectures that are not susceptible to loss of control events

2) Remote sensing of atmospheric hazards that may trigger upset conditions: convective weather, clear air turbulence, wake turbulence, icing flight conditions

3) Portrayal of and decision support for the pilot of geospatial location, extent, and relative movement of atmospheric hazards to enable flight around them

4) Relationship of air traffic operations to potentially de-stabilized maneuvering

5) Envelope protection and lockout devices to prevent unsafe energy states

6) Training to avoid hazards that could lead to loss of control

Detect: detection is tied to the detect/warn category of mitigations and these mitigation strategies but may also include training to recognize the onset of a hazardous situation:

1) Sensing immediate occurrence of de-stabilizing flight conditions

2) Sensing the vehicle condition (including damage, degradations, and ice accretion) that may create, promote, or trigger a loss of control event, correctly interpreting sensor input, and alerting with sufficient accuracy and look-ahead to facilitate an improved response from the pilot or onboard systems, or both

3) Pilot awareness and cueing of unusual flight attitudes or energy states, and other conditions suggesting the potential onset of a loss of control event

4) Training to recognize external hazards such as weather, turbulence, and wake vortex conditions.

5) Adverse vehicle-pilot interactions potentially leading to loss of control events, considering current and novel flight configurations, with and without intermediary flight control or stability-augmentation systems

Recover: recovery is the last line of defense and has strong ties to the procedures/training category, but may also benefit from automatic systems, safety devices, and warning devices to aid in the recovery of the vehicle. These mitigations may include:

1) Piloted (manual) control of flight vehicles in an upset or loss of control flight condition; may include training, procedures, and technologies to mitigate problematic behaviors including pilot cueing and stability augmentation technologies

2) Automatic recovery of flight vehicles from an upset or loss of control flight condition

3) Flight dynamic models of the post stall environment.

\section{Stakeholder Viewpoints on Aircraft Loss of Control}

For the purposes of this study, stakeholders are groups with an interest in aircraft loss of control. Stakeholders consist of regulatory agencies, research groups, air carriers and operators of aircraft, and manufacturers of aviation equipment. The study team members communicated with stakeholders and collected inputs in order to gain insight into the most pressing issues facing regulatory agencies, operators, and equipment manufacturers, related to loss of control. Over thirty stakeholders from the following organizations were interviewed;

1) Regulatory agencies, such as the FAA and the NTSB

2) Operators, such as the Air Line Pilots Association (ALPA), commercial pilots, and safety directors for airlines

3) Manufacturers, such as The Boeing Company, Airbus, S.A.S., and Honeywell International

4) Other organizations, such as CAST, NASA, Calspan, and Flight Safety International.

The LOC study team's discussions with stakeholders revealed some consistently conveyed ideas describing the most important mitigations for the loss of control hazard.

Envelope protection, envelope limiting and energy management (Avoid LOC). There are many causal factors that lead to exceeding an aircraft's flight-qualified envelope and normal operating envelope. These include spatial disorientation, upsets, crew inattention, poor energy management, mode confusion, improper procedures, and improper training. Stakeholders indicated that a high-priority mitigation toward preventing LOC is inhibiting an otherwise healthy aircraft from entering an unsafe condition. There are two schools of thought that have shaped the design approaches to envelope protection systems: one is to utilize automated systems to prevent the aircraft from exceeding the safe operation envelope, and the other is to give the crew all the aircraft control authority they need to recover from a loss of control situation. Potential mitigations include:

1) Envelope protection: understand the benefits and identifying potential hazards 
2) Envelope limiting: a new concept similar to envelope protection that incorporates the benefits of envelope protection but allows full aircraft control authority when such is demanded by the pilot. Identification of human factors hazards with unanticipated use is crucial for successful implementation.

3) Displays and automation for improved energy management

4) Automatic use of the propulsion system for envelope protection: thrust asymmetry identification and protection, use of integrated propulsion control for energy management, upset prevention and recovery

5) Partnerships to participate in verification and validation of these technologies.

Improved automation for human factors Mitigation (Avoid LOC). Stakeholders indicated that complexity of automatic systems, poor system architecture and a lack of human factors considerations in automatic systems are a key causal factor in aircraft loss of control. Potential mitigations include;

1) Reduced complexity in automation interfaces

2) Improved models of systems for increased pilot understanding

3) Improved feedback to the pilot about the state of automatic systems

4) Improved coordination between autopilot and autothrust systems

5) Automatic prevention of loss of control and pilot aids for recovery from a loss of control event.

6) Reduced "startle factor" for changes in automation ("bark before bite")

Training for upset prevention and recovery (Avoid, Detect, and Recover from LOC). Stakeholders are widely divided on the topic of training for loss of control recovery and prevention. All stakeholders agree that training to address loss of control prevention is key, but disagreements begin when attempting to determine the point in the flight envelope at which the training should end. For example, some manufacturers insist that simulation training should end at the point that the stick-shaker or stall warning is activated. The Upset Recovery Training Aid (URTA) ${ }^{11}$ developed by The Boeing Company, Airbus, S.A.S., and Flight Safety International is a reference for raising awareness about the flight dynamics of an aircraft in an upset condition, but is mostly used for academic purposes with limited application in the simulation. Stakeholders indicate that this document is not widely used in standard training curriculum, but is used by some vendors for elective training. The primary arguments against upset recovery training (URT) in simulators and surrogate aircraft are the potential for negative training, the lack of proven effectiveness, and the cost associated with model development and validation beyond the normal flight envelope. Pilot unions and operators are at odds with regard to upset prevention and recovery training. The pilots would like more training and the operators point to the phenomenal safety record of commercial aviation. Stakeholders indicated some key needs toward addressing LOC prevention and recovery training:

1) Conduct research that may be used to develop training products for externally-induced loss of control (icing, wind shear, wake vortex, turbulence, heavy rain). To ensure system-wide knowledge of externally-induced loss of control, training products should target flight crews, ground crews, aircraft operator dispatchers, and air traffic controllers.

2) Identify the most effective way to train pilots to mitigate loss of control events:

a) Determine effective ways to utilize the URTA in training.

b) Investigate the advantages and hazards associated with using motion-based and fixed-based simulations for training.

c) Perform research to understand where motion in simulation is most effective (seat cushion, gyroscopic devices, in-flight simulation, aerobatic training).

d) Prevention and recovery training: perform research that would give regulators, manufacturers, and operators guidance on the effective use of prevention training and the appropriate use of recovery training.

e) Research to determine when URT should be introduced to pilots during their career and how often to train for upset recovery to maintain proficiency.

Aerodynamic and dynamic model development for upset prevention and recovery (Recover). Stakeholders that are both for and against URT in simulators acknowledge the expense of developing models outside of the normal flight envelope (that is, flight within the linear region of angle of attack and sideslip) and that the models required for upset recovery are specific to each aircraft model. This implies a tremendous development cost in order to develop representative models for the numerous aircraft models. Of significant concern to stakeholders is adequately modeling aircraft dynamics beyond the nominal flight envelope or in the presence of external influences such as wake vortex or icing. Inaccurate modeling may lead to negative training and ultimately loss of life as evidenced by the 2004 crash of AA587. ${ }^{12}$ Stakeholders indicated that some key needs in the areas of aerodynamic and dynamic model development for upset prevention and recovery are:

1) Methods for accurate and cost-effective modeling outside the normal flight envelope

2) Development of generic models for upset prevention and recovery that include:

a) Multiple configurations 
b) Generic trends in models that can be used in training

c) Evaluate the effectiveness of generic models in training for specific aircraft types

d) Generic models that do not contribute to negative training

3) Research to determine control effectors most appropriate for loss of control recovery:

a) Control effectiveness in unusual attitudes

b) Use of the propulsion system as an effector

c) Control allocation strategies.

Detection and notification of pending upset condition (Detect). Stakeholders consistently emphasized the need to identify the development of a pending upset condition and provide the crew with sufficient information so they can take appropriate action to prevent an upset. Quite often the crew are caught off guard at the onset of an upset condition and have only seconds within which to identify the correct response. Incorrect responses may lead to an unrecoverable condition. Technologies are needed that:

1) Identify and warn of degraded energy states

2) Provide asymmetric thrust detection and notification

3) Identify and notify of spatial disorientation

4) Predict and mitigate PIO

5) Detect icing conditions and buildup and provide notification

6) Detect aircraft aerodynamic changes using real time system identification.

\section{Most Significant Causal Factors for Aircraft Loss of Control}

In response to the short time frame of the NASA loss of control study, the LOC team developed a hybrid approach to rapidly identify the most significant causal factors. The LOC team gathered four types of information pertaining to loss of control accidents: statistical data; individual accident reports that cite loss of control as a contributing factor; previous meta-analyses of loss of control accidents; and inputs solicited from aircraft manufacturers, air carriers, researchers, and other industry stakeholders. By using this approach, the LOC team concluded that the most significant category contributing to loss of control is human-induced causal factors. Typically this means that an otherwise healthy aircraft experiences a loss of control due to inappropriate human action. At a distant second and third place are causal factors related to systems-induced LOC and environmentallyinduced LOC.

The accident and incident statistics indicate that when a loss of control event occurs, it is most often a result of human error. Unfortunately, there are no statistics to indicate how often a human has intervened to prevent loss of control. Clearly, having a pilot is beneficial; however, the loss of control study team has identified important causal factors related to loss of control in which human error is involved. Providing tools for training and aiding the pilot to avoid, detect, prevent, and recover from, loss of control is an important impact the aviation community can make toward reducing loss of control events.

\section{A. Human-Induced Loss of Control}

Human-induced loss of control is by far the most important category to address within the aircraft loss of control hazard. The LOC study team categorized the most prominent human-induced loss of control causal factors:

1) Manual handling errors

2) Poor energy management

3) Automation effects on human-induced loss of control

4) Spatial disorientation and improper procedures

Manual handling errors. Manual handling errors were flagged by a number of loss-of-control accident analyses that cite inappropriate or erroneous control inputs by the flight crew in response to abnormal events or flight regimes. These accidents raise the question of "To what extent pilots are being trained to handle such events?" In the past, a larger proportion of air carrier pilots came from military aviation backgrounds. These pilots typically received extensive aerobatic training and left the training environment comfortable flying in a variety of aircraft attitudes, usual and unusual. Pilots who are trained in the general aviation environment receive minimal training in flying in or recovering from unusual attitudes. In fact, the current standard is to train commercial pilots in the simulator on upset recognition and stall recognition but not to simulate upset recovery. These pilots acquire the feel of an aircraft in linear, stable flight regimes but do not necessarily understand the limits of the flight envelope. Some pilots electively pursue aerobatics training, but no such requirement presently exists for the issuance of any existing FAA pilot certificate or rating, or as a hiring requirement for employment with an air carrier. 
The arrival of advanced cockpit automation for the general aviation fleet, has created a trend away from teaching and practicing basic stick-and-rudder skills and toward teaching those skills that focus on the use and management of cockpit automation. Since in-flight training for upset recovery in large airplanes is generally considered an unacceptable risk, current training approaches focus on the ground training for upset awareness, and hands-on training that is conducted in flight simulators. Both of these methods have limitations, and concerns remain regarding the proper method to use to train for the wide variety of upsets than could occur.

Deterioration of manual flying skills due to increased reliance upon automation is a strong contributor to manual handling errors. Some airline policies and procedures favor the use of automation during most phases of flight, causing further deterioration of manual flying skills. This deterioration in skill provides further encouragement to place even more emphasis on automation and less emphasis on manual flying. Thus, when piloting skill is needed to prevent or recover from a loss of control scenario, the basic manual flying skills are absent, either never having been fully developed or having atrophied to dangerous levels.

The need for consistent implementation of upset training has been recognized by industry and government, which has led to focused technical conferences such as the Royal Aeronautical Society, Flight Simulation Group, June 2009, proposed mandated upset training (FAA-2008-0677, Notice No. 08-07) and the formation of working groups such as the International Committee For Aviation Training in Extended Envelopes (ICATEE). The CAST identified upset training as an important intervention strategy (JSAT Intervention \# 35912) and recommended specific research for addressing the limitations of upset training implementation. These activities and others have proposed research that should be addressed in order to advance upset training.

Poor energy management. In large airplanes, energy management refers to the ability to know and control the complex combination of the aircraft's airspeed and speed trend, altitude and vertical speed, configuration, and thrust. The penalty for improper energy management can be de-stabilized approaches, excessive pilot workload leading to distraction, and ultimately inadequate altitude or airspeed to recover from a loss of control event (for example, a stall). Poor energy management during flight phases in which the aircraft is close to the ground are most often unforgiving and lethal.

Many loss of control incidents or accidents can be attributed to improper management of airspeed, especially those leading to aerodynamic stall or departure from controlled flight. Some examples include inattention to airspeed during approach and landing (Colgan Air,in January 2009, and Turkish Airlines in February 2009) from which recovery becomes increasingly difficult as altitude decreases. This can be due to a wide range of factors including improper monitoring, distraction, sensor error or failure, or weather-related factors. Improper glide path control, which is especially critical during precision approaches, can lead to large control inputs and, consequently, excessive airspeed excursions.

Several accidents appear to have occurred because of a lack of awareness of a degrading energy state. The reason for this is not clear, but issues include autoflight monitoring and warning, workload, and distractions. In the event of excessively low airspeed or stall, current transport airplanes typically rely on stall warning systems such as stick-shakers as the principal mitigation to prevent loss of control. The Turkish Airlines (February 2009) crash occurred due to an altitude sensor failure during approach that in turn caused a premature autothrottle mode change. The experienced crew did not detect the decreasing airspeed condition until the stall occurred, resulting in the accident.

Several accidents have occurred in which the pilot intentionally overrode the stall inhibitor system (stickshaker) for no apparent reason. Research is needed to address inadvertent stick-shaker override and the effectiveness of stall prevention systems as well as the human interactions with and tactile cues provided by these systems. The Machiques, Venezuela MD-82 crash (August, 2005) involved a high-altitude stall in which the stick-shaker was reported to have been activated and maintained to ground impact. This behavior has been documented for numerous accidents, and raises the issue of the effectiveness of stall prevention systems. It is recognized that a lack of training may be partly to blame, because exposure to stall prevention systems is not part of the training curriculum. The first time a pilot experiences a stick-shaker is usually during a revenue flight with passengers on board.

Automation effects on human-induced loss of control. The most prominent causal factors related to automation effects on human-induced loss of control are pilot misunderstanding of automation, poor feedback to the pilot about the state of automation systems, and failure of an automation system. The number of automated systems in the cockpit continues to steadily increase, as does the number of features provided by such systems, along with the number of operational modes that interact with one another to produce complex behaviors that are difficult to understand and predict. In addition to the complexity of normal systems operation, the history of accidents and incidents also points to the problem of "corner cases:" cases in which the automation exhibits behaviors that are unexpected or undesired that have gone undetected during the validation and verification stages of design. 
A second contributor to pilot confusion about automation is the poor feedback often provided by automated systems. A number of accidents have occurred when an automated system detected an anomalous condition, attempted to correct the anomaly, reached its operational limits, and then suddenly handed control of the aircraft back to the flight crew. Surprised and out of the loop, the flight crew is often unable to respond in time to save the day.

A third contributing factor to pilot confusion regarding automation stems from the reliability of the automated systems themselves. Many types of system failures rarely occur, giving pilots few opportunities to practice dealing with them. As well, failures may occur up-and-away or close to the ground, leaving little time for diagnosis and progression through emergency procedures.

\section{B. Systems-Induced Loss of Control}

Systems-induced loss of control is a distant second to human-induced loss of control causal factors. Modern aircraft systems are extremely safe. Design standards for flight-critical systems have failure probabilities such that failure should never occur during the operational life of all airplanes of one type. ${ }^{13}$ It is typically assumed that flightcritical components have a failure probability rate of $10^{-9}$ per hour of operation. ${ }^{14}$

Even with stringent reliability guidelines, systems failures of flight-critical systems do occur. According to Reveley, ${ }^{1}$ system component failure/malfunction (SCFM) or damage is the trigger in approximately one third of Part 121 LOC accidents. In Part 135 operations, approximately 11 percent of LOC accidents are triggered by SCFM or damage, and in general aviation (Part 91 operations) they account for 8 percent of the LOC accidents.

System faults may be the direct cause of loss of control, they may be a trigger which leads to a loss of control, or they may be a contributing factor in a loss of control event. Triggers may originate from onboard the aircraft or come from the air traffic system within which the vehicle is operating.

Some systems-induced loss of control accidents are not caused due to failure or damage, but may be the result of a poor system design that triggers a loss of control event. Examples include unintended use of the automatic system, designs not accounting for unforeseen hazards, or a lack of redundancy management. The systems are functioning properly, but they were not designed to be resilient to all possible anomalies. The following is a list of causal factors associated with systems-induced loss of control:

1) Poor systems design:
a) Poor energy management systems
b) Poor redundancy management
c) Autopilot modes leading to loss of control
d) PIO

2) Aircraft system faults or failures or damage (non-propulsion):

a) Erroneous sensor data

b) Loss of control power, authority, or effectiveness

c) Display errors

3) Propulsion system faults/failures/damage

4) Fire

Design of aircraft systems has evolved over decades. Systems features and functionality have improved, but maintain many of the characteristics from previous designs. This is often due to an operational need for commonality between aircraft and systems or because of the certification process. While many design features are being improved and made safer, there are still many that continue to affect the loss of control accident statistics. The following discusses some examples of systems design characteristics that contribute to loss of control events.

Legacy systems are still in use, that have incorporated poor redundancy management systems. For example, recent accidents were the result of the pilot manually selecting a faulty air data probe. New designs incorporated into the A380 (Airbus, S.A.S., Toulouse, France) and B787 (The Boeing Company, Chicago, Illinois) provide a reasonable estimate of air data, even in the event that all air data probes are faulty, through the use of sensor fusion between inertial and air data systems.

As previously discussed, improper use of autopilot modes continues to be a problem. The human operator often receives the blame, but the root cause may be the system design. For example, there is no requirement for coordination between the autopilot and autothrottle systems. They may be used independently of each other with only a small annunciation to the pilot. An incident cited in the 2008 CAST report on mode confusion cites a B777 (The Boeing Company, Chicago, Illinois) that attempted to take off with the autopilot turned on and the autothrottles turned off. The crew didn't realize the misconfiguration until the pilot flying attempted takeoff rotation and was prevented from becoming airborne by the autopilot. ${ }^{15}$ A requirement for coordination between autopilot and 
authothrottles, or logic to prevent engagement of the autopilot on the takeoff roll would have prevented this incident. There are numerous other examples in which the autopilot and autothrottles have been inappropriately used together. Incorporation of logic to force their proper use would prevent these kinds of loss of control events. Other examples include display malfunctions that have occurred due to poor verification and validation while integrated into the cockpit.

The startle factor often occurs when the autopilot disengages and hands control to the pilot in a highly dynamic transient condition. Better designs that incorporate warnings and more graceful transition of control should be required.

Energy management related to aircraft systems continues to be a problem that can cause loss of control. The aircraft, for a variety of reasons, is allowed to get slow and low to the ground, where triggers for loss of control are unforgiving. The Birgenair accident (February, 1996) was an example of a situation in which systems failures, misinterpretation of systems annunciation, poor energy management, and lack of recognition of a stall, all contributed to the lack of recovery from the loss of control event.

Poor energy management may result due to faults, failures or damage. During a system failure there may be reduced engine performance, increased drag due to external damage, or a loss of control surface effectiveness. These factors typically result in an increased workload for the crew, reduced maneuvering margins, nonlinear flight dynamics, and poor handling qualities. Each of these factors may result in poor energy management and act as a trigger for a loss of control event. In an emergency, the crew must first be able to retain control of the aircraft, then manage the energy state, and ultimately return the aircraft safely to the ground. Effective tools are needed for the pilot to safely control the aircraft and manage the energy state during one of these events to prevent a loss of control trigger.

Strategies for airplane control during faults, failures, or damage must consider the limitations of the pilot in recognizing and adapting to abnormal handling qualities. Pilots currently learn manual control characteristics for a normal, or unimpaired, airplane by way of flight and simulator training. Pilot training for abnormal conditions is generally limited to those needed for certification requirements, such as engine failures, and certain control surface failures, such as runaway trim. It must be recognized that the ability of, or opportunity for, a pilot to learn the control strategy and available envelope for an impaired aircraft is extremely limited and probably unrealistic for many failures or damage cases. Based on data from previous accidents, it can be assumed that the pilot may have only a few seconds within which to develop and learn a control strategy to safely maneuver the airplane. This accomplishment essentially requires the skills of a test pilot. In the cases of United Airlines Flight 232 (July, 1989) and the DHL A300 (November, 2003) the aircrews were successful in maneuvering the aircraft because they had adequate time after the event occurred to learn how to fly their "new" airplane, a luxury which typically would not exist during a significant failure or damage scenario. The difficulty in developing this skill is highlighted by recent in-flight upset training programs in which rudimentary control failures are a significant piloting challenge.

Accurate sensor data are critical to monitoring critical aircraft states and for control system functions. For example, airspeed and altitude measurements are critical for proper energy management and stall avoidance. Airspeed and altitude sensors are susceptible to errors due to pitot-static system malfunctions; some accidents have been attributed to conflicting information between redundant systems.

Several recent accidents highlight the impact of erroneous sensor data. The Birgenair accident (February, 1996) was the result of erroneous airspeed data, although several minutes transpired from first indication of the failure until the crash. In this case, the captain's airspeed indicator was erroneous due to a blocked pitot tube that gave the indication that airspeed was increasing during climbout. This in turn led to a stall from which recovery was never achieved although the stick-shaker was activated. The Korean Air accident (December, 1999) involved an unreliable attitude director indicator (ADI) that resulted in excessive bank angle and subsequent ground impact. In 2008, two separate Qantas Airline flights experienced autopilot disengage due to a failure in the air data inertial reference unit (ADIRU). During the first flight, the A330 (Airbus, S.A.S., Toulouse, France) experienced a severe pitch-over resulting in significant injuries to unrestrained passengers.

Recent designs exist which incorporate sensor fusion between the air data and inertial systems. Accidents such as the February, 1996 Birgenair accident would not occur with these systems because ADIRU technology provides a valid air data estimate even with all of the static ports blocked. As stated earlier, the B787 (The Boeing Company, Chicago, Illinois) has already integrated this type of system. Birgenair-type accidents, however, have been replaced by Qantas-type accidents likely due to shortcomings in verification and validation methods.

A number of different propulsion-system related causal factors have been identified that resulted in untenable asymmetric thrust for an aircraft in flight or in insufficient power during takeoff or landing such that the loss of control of the aircraft resulted. Loss of control accidents rarely have a single cause, but are, rather, a result of a number of malfunctions or unfamiliar piloting situations occurring simultaneously or in rapid succession. 


\section{Environmentally-Induced Loss of Control}

Factors external to the aircraft are often a significant causal factor in loss of control accidents. In today's aviation world, very few accidents have a single cause. Typically, a number of causal factors must be lined up to cause a loss of control accident. Very often the trigger that initiates an accident sequence is an external environmental factor. These factors are predominantly weather-related, however, they can also be traffic-related (such as wake vortices) or biologic (such as bird strikes). Based on NTSB, FAA, and NASA database information, the five environmentally-induced loss of control causal factors have been prioritized. Table 6 presents the causal factors in priority order for environmentally-induced loss of control.

Table 6. Environmentally-induced loss of control causal factor frequency ( $\left.\operatorname{Reveley}^{1}\right)$.

\begin{tabular}{lccc}
\hline \hline Causal factor & $\begin{array}{c}\text { Parts121 and 135, } \\
\text { scheduled } \\
\text { (40 LOC accidents) }\end{array}$ & $\begin{array}{c}\text { Part 135, unscheduled } \\
\text { (159 LOC accidents) }\end{array}$ & $\begin{array}{c}\text { Part 91 } \\
(4,287 \text { LOC accidents })\end{array}$ \\
\hline Icing & $54 \%$ & $27 \%$ & $6 \%$ \\
Turbulence & $11 \%$ & $22 \%$ & $20 \%$ \\
Degrading visibility & $9 \%$ & $14 \%$ & $18 \%$ \\
Heavy rain & $6 \%$ & $5 \%$ & $2 \%$ \\
Low-level wind shear & $4 \%$ & $3 \%$ & $2 \%$ \\
\hline \hline
\end{tabular}

These environmental hazards can either directly or indirectly cause a loss of control accident. For example, a severe ice accretion can cause such drastic aerodynamic degradation that the aircraft becomes uncontrollable; icing can cause a drag increase such that an inattentive flight crew lets the speed degrade to wing stall; or an ice accretion can limit control effectiveness so that in an emergency maneuver the aircraft becomes uncontrollable. While all of these accident scenarios would play out very differently, they can all be described as having been triggered by the aircraft's initial encounter with atmospheric icing conditions.

Just as the same environmental trigger can cause different accident scenarios, the resultant loss of control accident can be prevented by way of several potential mitigations. Most of the environmental causal factors can be completely avoided. Avoidance results in the lowest potential for harm to the aircraft its crew and passengers, thus, it is always the preferred option. Avoidance, however, is rarely 100 percent effective, so reliance on early detection and exit is the next best strategy. If both of these opportunities are missed, the final possible mitigation to prevent a loss of control accident is recovery. The level of risk increases as a potential accident scenario plays out, and the number of potential mitigations correspondingly decreases, thus the earlier a loss of control causal factor is mitigated, the better. Avoidance mitigations, therefore, are almost always preferred over detection and recovery. Accordingly, research to enable avoidance mitigations should in general be favored over that required for detection and recovery, other factors being equal. Similarly, detection mitigation related research should be favored over that required for recovery mitigations. Other factors to be considered in prioritizing research include such things as probability of success, expected time to implementation, cost, and likelihood of implementation.

\section{Recommended Mitigations and Technical Challenges}

A sympathetic read of loss of control accidents leaves little hope of a reduction in occurrence if efforts toward improvement are aimed in a single direction or remain within a single category. Recognizing this, the study team has attempted to identify as many causal factors as possible within each of these three categories, and to recommend potential mitigations that might help eliminate the presence of each causal factor during flight. While examining aircraft loss of control across the spectrum of causal factors, the team observed several recurring themes. A review of these areas indicates there are some foundational activities that support mitigations for a range of causal factors.

1) Improved health monitoring of aircraft systems is seen to contribute to mitigation strategies related to onboard system failures and external influences such as icing.

2) The need for improved modeling in adverse conditions such as outside-the-envelope flight is a fundamental element in many loss-of-control mitigations, and supports the development of manual and automatic prevention, recovery, and control strategies. This includes tools for model development, systems 
identification, and strategies for developing generic models that apply to multiple platforms. These activities may also support modeling for ice contamination and damage conditions.

3) Research to support improved loss of control training for prevention and recovery of aircraft loss of control is a first line of defense. This includes appropriate use of theoretical training on the physics of loss of control, simulation-based training, and in-flight simulation.

4) Research in identifying maneuver boundaries and limiting the flight envelope is also seen to be beneficial for a range of mitigations, encompassing human, environmental, and systems-induced LOC events.

5) Research to provide the pilot with increased awareness about the health and state of the aircraft and its automatic systems in order to avoid a loss of control event.

6) Integrated aerodynamics and propulsion control that incorporates energy management will provide mitigation for many loss of control hazards.

7) Automatic control system technology to provide good handling qualities at all times in order to avoid a loss of control event.

8) Data mining of accident reports or incident reports and flight operational quality assurance (FOQA) data to identify causal factors in loss of control. These actions will enable the identification of patterns, trends, and behaviors that lead to loss of control and allow changes to be made in training and procedures to prevent future loss of control events.

9) System safety analysis of NextGen operational impact on LOC so as to not introduce new hazards as NextGen technologies and operational models are brought online.

10) Research to support improved verification and validation of complex systems.

These mitigation strategies and related foundational areas cross all operational regimes from commercial to general aviation.

The programmatic challenges for addressing loss of control lie in selecting the sequence for developing the loss of control mitigations. Choices must be made regarding training for near-term impacts versus technology development for long-term impacts. Mitigations focused on training and recovery from loss of control will eventually reach a point of diminishing returns because of the insertion of human operators into a complex system. Technology solutions developed while NextGen is being formulated will be subject to currently unidentified hazards, requiring significant and expensive redesign. A blended investment that allows development of near-term and long-term solutions is required in order to make an immediate and lasting impact on the loss of control accident statistics.

\section{Conclusions}

Drawing upon statistics, accident reports, and analyses, and inputs solicited from industry stakeholders, the NASA Loss of Control study team developed a list of causal factors for loss of control accidents. Although the causal factors have been loosely organized into three categories: human- or pilot-induced, environmentally-induced, and systems-induced, no single category is solely responsible for loss of control accidents. Rather, accidents occur when combinations of breakdowns happen across human and engineering systems, often in the presence of threats posed by the external environment.

Human-induced causal factors are a stronger contributor to loss of control accidents when compared to environmentally-induced and systems-induced causal factors. For near-term impacts on human-induced loss of control, mitigation strategies should focus on loss of control prevention and recovery training. Improved loss of control prevention and recovery training techniques have the added benefit of providing loss of control mitigation in Part 91 operations, in which technology-based solutions are less likely to have an impact. The implication is that better models of the post-stall environment are required in order to develop appropriate training material and avoid negative training. Technology-based solutions such as automatic energy management systems, envelope protection and envelope limiting, better human-machine interfaces to automation, improved health monitoring of aircraft systems, and improved verification and validation methods for increasingly complex systems are required for longterm impacts.

Avoidance and detection of loss of control events are more important strategies when compared to recoverybased mitigations, however, development of recovery-based mitigations are also required in order to ensure complete coverage when "breaking the chain" of events in a loss of control scenario. Onboard systems that eliminate, or protect the aircraft from entering, a loss of control scenario are most effective. Avoidance and detection of loss of control events should not be limited to real-time, onboard systems, but should include data mining of incident reports, accidents reports, and flight operations quality assurance data to identify trends and conditions that 
lead to loss of control so that the precursors may be eliminated or minimized. Off-board solutions should also include technologies to avoid weather and atmospheric related hazards such as icing and wake vortex encounters.

Special attention should be paid to the Next Generation Air Transportation System as new technologies and operational models are developed to identify and mitigate new loss of control hazards. The introduction of new technologies that are intended to mitigate hazards can introduce unforeseen hazards. As Next Generation Air Transportation System technologies and operational procedures are integrated into the national airspace, we may see a rise in loss of control accidents because of increased traffic and congestion and changes in the way the national airspace is used. Early identification and mitigation of potential hazards will continue to be a challenge in this evolution. Improved methods for verification and validation of Next Generation Air Transportation System technologies will become increasingly important as the complexity of onboard and off-board systems increases.

Aircraft loss of control will continue to be a challenging hazard because of the nature of flight, the demands on aircraft performance and capacity in the airspace system, and the increasing complexity of operations, onboard and off-board systems. Continued diligence by operational, research, and regulatory organizations is required in order to improve the civil aviation safety record.

\section{Acknowledgments}

The concepts developed and presented in this report are the result of the dedication of the NASA Loss of Control study team: John V. Foster (Langley Research Center), Stephen M. Casner (Ames Research Center), Andrew L. Reehorst (Glenn Research Center), Harold E. Addy Jr. (Glenn Research Center), Gautam Shah, (Langley Research Center) and Jessica Nowinski (Ames Research Center). Additionally, the Loss of Control study team benefited from the consultation of many stakeholders, both inside and outside NASA.

\section{References}

${ }^{1}$ Reveley, M. S., Briggs, J. L., Evans, J. K., Sandifer, C. E., and Jones, S. M., "Causal Factors and Adverse Conditions of Aviation Accidents and Incidents Related to Integrated Vehicle Aircraft Control," NASA/TM-2010-216261 (to be published).

${ }^{2}$ Commercial Aviation Safety Team (CAST), “JSAT Loss of Control: CAST Approved Final Report,” Dec. 2000.

${ }^{3}$ The Boeing Company, "Statistical Summary of Commercial Jet Airplane Accidents Worldwide Operations 1959-2008," Jul. 2009.

${ }^{4}$ Smith, B. E., “Analysis of Part 121 Loss of Control Accidents Involving Fixed-Wing Commercial Aircraft Worldwide; 1987-2007," Mar. 2009

${ }^{5}$ Lambregts, A. A., Nesemeier, G., Wilborn, J. E., and Newman, R. L., “Airplane Upsets: Old Problem, New Issues," AAIA-2008-6867, Aug. 2008.

${ }^{6}$ Leveson, N. G., Safeware: System Safety and Computers, Addison-Wesley, 1995.

${ }^{7}$ National Aeronautics and Space Administration (NASA), "Hazard Management Procedure," DCP-S-002, 2010, available from the Dryden Flight Research Center Management Systems Office.

${ }^{8}$ Sabatini, N. A. "Downward Pressure on the Accident Rate," URL: http://www.faa.gov/news/speeches/news_story.cfm?newsId=7170, [cited 27 July 2010].

${ }^{9}$ Belcastro, C. M., "Potential Future Research Directions to Prevent Aircraft Loss-of-Control Accidents," presented at the Langley Research Center, Nov. 2009.

${ }^{10}$ Young, S. D., electronic mail from Steven D. Young to Amy R. Pritchett, Hampton, Virginia, Jun. 2009.

${ }^{11}$ Federal Aviation Administration (FAA), “Airplane Upset Recovery Training Aid, Revision 2,” Nov. 2008.

${ }^{12}$ National Transportation Safety Board (NTSB), "In-Flight Separation of Vertical Stabilizer, American Airlines Flight 587, Airbus Industrie A300-605R, N14053, Belle Harbor, New York, November 12, 2001," NTSB/AAR-04/04, PB2004-910404, Notation 7439B, Oct. 2004.

${ }^{13}$ Federal Aviation Administration (FAA), "Systems Design and Analysis,” AC No. 25.1309-1A, Jun. 1988.

${ }^{14}$ Rushby, J., "Software Verification and System Assurance," 7th IEEE International Conference on Software Engineering and Formal Methods (SEFM), Nov. 2009.

${ }^{15}$ Commercial Aviation Safety Team (CAST), "Mode Awareness and Energy State Management Aspects of Flight Deck Automation," Safety Enhancement 30, Revision 5, Final Report, Aug. 2008. 


\section{Aircraft Loss of Control Causal Factors and Mitigation Challenges}

Steve Jacobson

NASA Loss of Control Study team Lead NASA Dryden Flight Research Center

Edwards, CA 


\section{Outline}

- Introduction

- NASA Loss of control study team approach

- Background on aircraft loss of control accident statistics

- Causal factors

- Recommended mitigations

- Supporting Research 


\section{Abstract}

Loss of control is the leading cause of jet fatalities worldwide. Aside from their frequency of occurrence, accidents resulting from loss of aircraft control seize the public's attention by yielding a large number of fatalities in a single event. In response to the rising threat to aviation safety, the NASA Aviation Safety Program has conducted a study of the loss of control problem. This study gathered four types of information pertaining to loss of control accidents: statistical data; (2) individual accident reports that cite loss of control as a contributing factor; (3) previous meta-analyses of loss of control accidents; and (4) inputs solicited from aircraft manufacturers, air carriers, researchers, and other industry stakeholders. Using these information resources, the study team identified the causal factors that were cited in the greatest number of loss of control accidents, and which were emphasized most by industry stakeholders. This report describes the study approach, the key causal factors for aircraft loss of control, and recommended mitigation strategies to make near-term impacts, mid-term impacts, and Next Generation Air Transportation System impacts on the loss of control accident statistics. 


\section{Loss of Control defined}

Definition

2000 CAST JSAT

Report on Loss of Control
Loss of control to includes significant, unintended departure of the aircraft from controlled flight, the operational flight envelope, or usual flight attitudes, including ground events. "Significant" implies an event that results in an accident or incident. This definition excluded catastrophic explosions, CFIT, runway collisions, complete loss of thrust that did not involve loss of control, and any other accident scenarios in which the crew retained control. This does include loss of control, due to aircraft design, aircraft malfunction, human performance, and other causes 


\section{Current NASA LOC Research: IRAC-FAST Objectives}

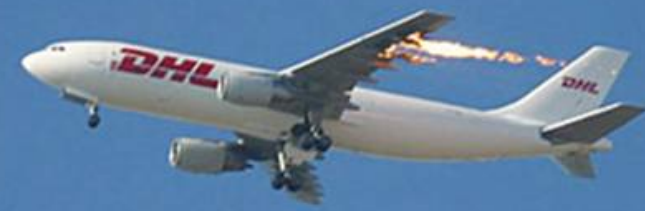

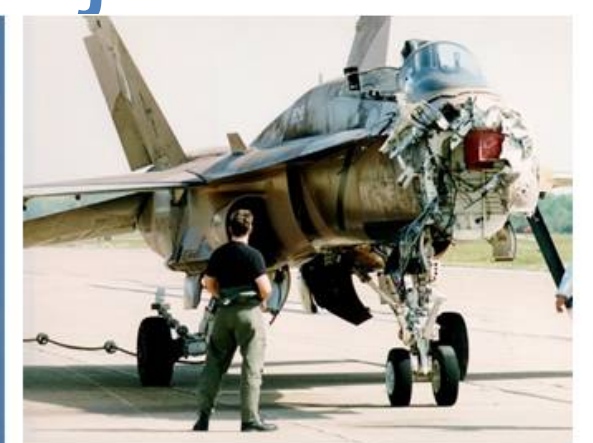

Can Modern Control

Systems Help the Pilot Out

Even More Than

Traditional Methods????

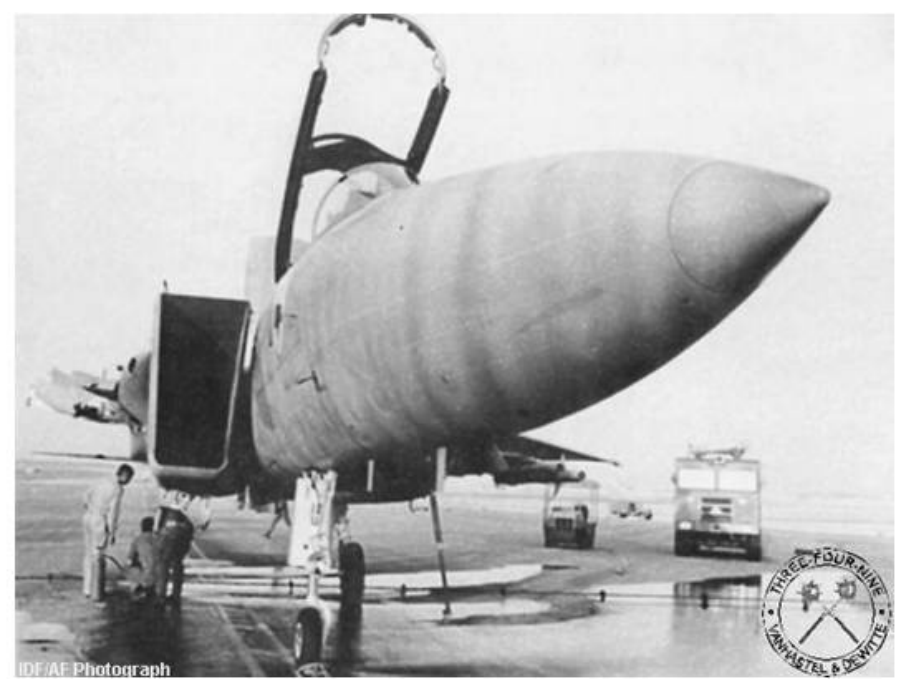

- The above were survivable accidents; IRAC maybe able to help more.

- Objectives

- Regain a Stable Platform

- Evaluate Robustness metrics for nonlinear adaptive systems

- Maneuverability (can you fly it around)

- Control vehicle within new constraints / structural loads etc..

- Provide the ability to safely land the airplane

- Develop safest recovery trajectory

The current IRAC work falls under the mitigation categories of Avoidance and Recovery 


\section{Boeing's Annual Report (International accidents included)}

Fatalities by CAST/ICAO Common Taxonomy Team (CICTT)

Aviation Occurrence Categories

Fatal Accidents - Worldwide Commercial Jet Fleet - 1999 Through 2008

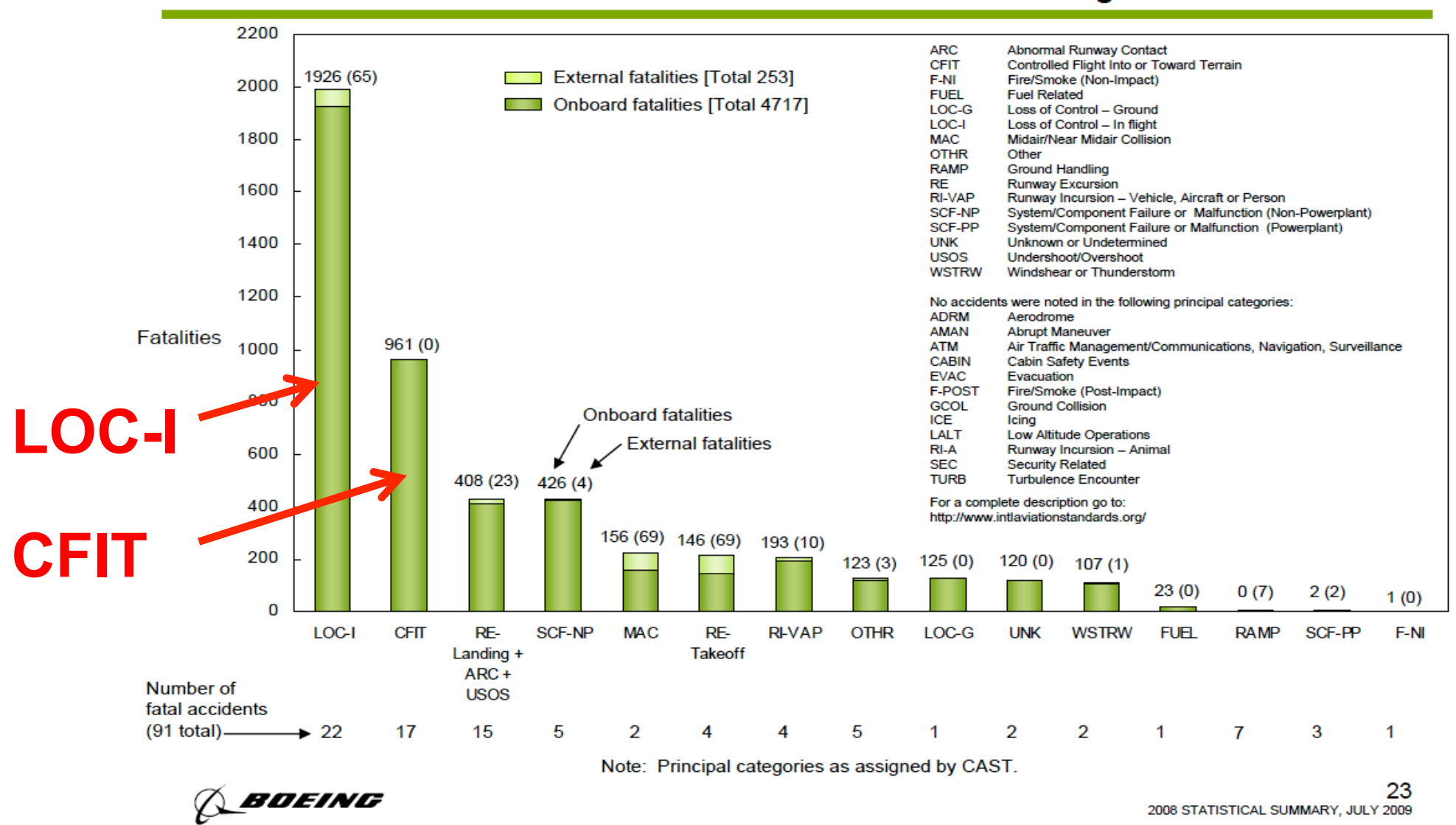




\section{LOC Study team objective}

- This study team is to provide a systematic, datadriven analysis of the fundamental research required to address loss of control,

- Fourth Quarter CY09

- Study team expertise

- All four NASA research centers represented

- Skills on the team: flight control, flight dynamics, loss of control, flight research, aircraft icing, human factors, flight training, pilot-human automation, human performance, and human error.

- A hybrid approach was adopted 


\section{LOC Study Team Approach (3 months)}

- Review statistical data; Statistics are good at categorizing accidents but don't provide much insight into mitigations

- Review some individual accident reports that cite loss of control as a contributing factor;

- Interviewed stakeholders

- Review previous meta-analyses of loss of control accidents; 


\section{LOC Study Team Approach (cont...)}

- Identified causal factors that were cited in the greatest number of loss of control accidents, and which were emphasized most by industry stakeholders.

- For each causal factor that was linked to loss of control, the team solicited ideas about what solutions are required and future research efforts that could potentially help avoid their occurrence or mitigate their consequences when they occurred in flight 


\section{Analysis of accidents in the Boeing Statistical Summary LOC-I category}

\begin{tabular}{|l|c|c|}
\hline $\begin{array}{l}\text { Causal factor } \\
\text { category }\end{array}$ & $\begin{array}{c}\text { \# Accidents } \\
\text { as Primary } \\
\text { CF }\end{array}$ & $\begin{array}{c}\text { \# Accidents as } \\
\text { Contributing CF }\end{array}$ \\
\hline $\begin{array}{l}\text { Pilot/human } \\
\text { induced }\end{array}$ & 16 & 22 \\
\hline $\begin{array}{l}\text { Environmental } \\
\text { induced }\end{array}$ & 4 & 5 \\
\hline $\begin{array}{l}\text { Systems } \\
\text { induced }\end{array}$ & 2 & 7 \\
\hline
\end{tabular}

LOC-I Accidents that occurred in each causal factor category 1999-2008

Accidents identified from the LOC-I category in the Boeing Statistical Summary of Commercial Jet Airplane Accidents1999 - 2008 


\section{Analysis of accidents in the Boeing Statistical Summary LOC-I category}

\begin{tabular}{|c|c|}
\hline Causal factor & \# Accidents w/CF \\
\hline Pilot/human induced & \\
\hline Improper Procedure & 10 \\
\hline Spatial disorientation & 6 \\
\hline Poor energy management & 6 \\
\hline Distraction & 5 \\
\hline Improper training & 5 \\
\hline Poor design & 2 \\
\hline Environmental induced & \\
\hline Weather & 3 \\
\hline Icing & 2 \\
\hline Wake vortex & 1 \\
\hline Systems induced & \\
\hline Aircraft systems failures & 5 \\
\hline Poor Design & 2 \\
\hline
\end{tabular}

Causal factors contributing to LOC-I commercial aircraft fatalities 1999 - 2008 


\section{Analysis of accidents in the Boeing Statistical Summary LOC-I category}

\begin{tabular}{|l|c|}
\hline Region & Number of fatal accidents \\
\hline Asia (ex China) & 6 \\
\hline Europe & 5 \\
\hline Africa & 4 \\
\hline Latin America/Caribbean & 3 \\
\hline CIS & 2 \\
\hline Middle East & 1 \\
\hline USA/Canada & 1 \\
\hline China & 0 \\
\hline
\end{tabular}

Regions where fatal LOC-I commercial aircraft fatalities occurred 1999-2008 


\section{Analysis of accidents in the Boeing Statistical Summary LOC-I category}

\begin{tabular}{|l|c|}
\hline Phase of flight & Number of fatal accidents \\
\hline Climb & 6 \\
\hline Take off & 5 \\
\hline Final approach & 3 \\
\hline Initial climb & 2 \\
\hline Cruise & 2 \\
\hline Initial approach & 2 \\
\hline Landing & 2 \\
\hline
\end{tabular}

Flight phase where fatal loss of control accidents occur 1999 - 2008 


\section{Observations from the accidents in the Boeing Statistical Summary, LOC-I}

- Finding 1: Out of the 22 accidents in the LOCI occurrence category, the leading causal factors come from pilot/human induced category

- Finding 2: For large aircraft, the majority $(95 \%)$ of recent LOC-I fatal accidents occur outside of the United States and Canada.

- Finding 3: The majority (81\%) of recent LOC-I accidents occur during flight phases where the aircraft is relatively close to the ground where there is little time for action, and where circumstances are unforgiving of mistakes. 


\section{Observations from the accidents in the Boeing Statistical Data}

- Finding 4: Flight crew deviation from prescribed procedure is a very significant factor in loss of control accidents.

- Finding 5: Spatial disorientation is a problem, but it occurs primarily outside of the United States.

- Finding 6: Poor energy management (e.g. aerodynamic stall) is a significant factor in loss of control accidents.

The Boeing Data only focus on Aircraft greater than 60,000 lbs. Further Insight into smaller AC were needed 


\section{NASA Systems Analysis Report of Aircraft Loss of Control}

- "Causal Factors and Adverse Conditions of Aviation Accidents and Incidents Related to Integrated Vehicle Aircraft Control" NASA TM-2010-216261

- Examines, Part 121, Part 135 scheduled and nonscheduled operations, and Part 91

- Dataset includes accidents and incidents from 1988 - 2004 


\begin{tabular}{|c|c|c|c|c|c|}
\hline \multirow[b]{2}{*}{ Type of events } & \multicolumn{5}{|c|}{ Operation Category } \\
\hline & Part 121 & $\begin{array}{l}\text { Scheduled } \\
\text { Part } 135 \\
\end{array}$ & $\begin{array}{c}\text { Non-Scheduled } \\
\text { Part } 135 \\
\end{array}$ & Part 91 & $\begin{array}{c}\text { Part } 91,135, \& 121 \\
\text { Combined }\end{array}$ \\
\hline Total Flight Hours & $251,751,143$ & $25,353,146$ & $49,588,000$ & $441,207,000$ & $767,896,289$ \\
\hline Total Accidents & 630 & 217 & 1115 & 24473 & 26435 \\
\hline LOC Accidents & $\begin{array}{r}26 \\
\text { (4\% of Total } \\
\text { Accidents) } \\
\end{array}$ & $\begin{array}{r}32 \\
(15 \% \text { of } \\
\text { Total }\end{array}$ & $\begin{array}{r}198 \\
(18 \% \text { of Total } \\
\text { Accidents }) \\
\end{array}$ & $\begin{array}{r}4961 \\
(20 \% \text { of Total } \\
\text { Accidents }) \\
\end{array}$ & $\begin{array}{r}5217 \\
(20 \% \text { of Total Accidents })\end{array}$ \\
\hline $\begin{array}{l}\text { LOC Accidents per } \\
\text { million flight hours }\end{array}$ & 0.10 & 1.26 & 4.03 & 11.24 & 6.79 \\
\hline Fatal Accidents & $\begin{array}{r}62 \\
(10 \% \text { of total } \\
\text { accidents })\end{array}$ & $\begin{array}{r}49 \\
(23 \% \text { of } \\
\text { total } \\
\text { accidents })\end{array}$ & $\begin{array}{r}293 \\
(26 \% \text { of Total } \\
\text { Accidents })\end{array}$ & $\begin{array}{r}4815 \\
(20 \% \text { of Total } \\
\text { Accidents })\end{array}$ & $\begin{array}{r}5289 \\
(20 \% \text { of Total Accidents })\end{array}$ \\
\hline $\begin{array}{l}\text { Fatal LOC } \\
\text { Accidents }\end{array}$ & $\begin{array}{r}21 \\
(81 \% \text { of } \\
\text { LOC } \\
\text { accidents }) \\
\end{array}$ & $\begin{array}{r}19 \\
(59 \% \text { of } \\
\text { LOC } \\
\text { accidents }) \\
\end{array}$ & $\begin{array}{r}128 \\
\text { (65\% of LOC } \\
\text { Accidents) }\end{array}$ & $\begin{array}{r}2635 \\
(53 \% \text { of } \\
\text { LOC } \\
\text { Accidents) } \\
\end{array}$ & $\begin{array}{r}2803 \\
\text { (54\% of LOC } \\
\text { Accidents) }\end{array}$ \\
\hline Total Fatalities & 2165 & 328 & 698 & 9146 & 12337 \\
\hline $\begin{array}{l}\text { Fatalities in LOC } \\
\text { Accidents }\end{array}$ & $\begin{array}{r}1186 \\
(55 \%) \\
\end{array}$ & $\begin{array}{r}161 \\
(49 \%) \\
\end{array}$ & $\begin{array}{r}285 \\
(41 \%) \\
\end{array}$ & $\begin{array}{r}5178 \\
(57 \%) \\
\end{array}$ & $\begin{array}{r}6810 \\
(55 \%) \\
\end{array}$ \\
\hline Total Incidents & 7808 & 2234 & 2201 & 29520 & 41,763 \\
\hline LOC Incidents & 38 & 5 & 8 & 81 & 132 \\
\hline $\begin{array}{l}\text { LOC Incidents } \\
\text { per million flight } \\
\text { hours }\end{array}$ & 0.151 & 0.197 & 0.161 & 0.18 & 0.17 \\
\hline
\end{tabular}




\section{Observations from the data in the NASA \\ Systems Analysis study on LOC}

- Finding 7: More than half of LOC-I events result in an accident and more than half of those accidents are fatal.

- Finding 8: In approximately $1 / 3$ of Part 121 loss of control accidents, loss of control was due to a system component failure.

- Finding 9: Approximately 34\% of all fatal Part 121 accidents are LOC accidents

- Finding 10: In approximately 1/3 of Part 121 accidents, the NTSB determined control was not possible. 


\section{Mitigations}

- Mitigation Hierarchy (From system Safety Fundamentals)

- Design/Eliminate the hazard

- Safety devices to minimize risk

- Detect/Warn

- Procedures/Training

- Placards 


\section{Mitigation Classification for LOC}

- Avoid: Avoidance is usually tied to design of systems that eliminate the hazard and safety mitigations but may also include standard operating procedures and training to avoid loss of control scenarios.

- Detect: Detection is tied to the detect/warn category of mitigations and these mitigation strategies but may also include training to recognize the onset of a hazardous situation.

- Recover: Recovery is the last line of defense and has strong ties to the procedures/training category, but may also benefit from automatic systems, safety devices and warning devices to aid in the recovery of the vehicle. 


\section{Mitigation Development strategy}

- Near term impact (5-10 yrs): LOC Training, Better standard operating procedures

- Mid Term impact (5-20 yrs): IVHM, improved displays, aircraft attitude and energy management tools, envelope protection/limiting, improved automation and warning systems, adaptive control

- NextGen impact (Long term): Aircraft design, system architectures, improved V\&V 


\section{Mitigations and statistical summaries}

- Statistical Summaries don't do a good job of pointing to mitigations due to the loss of the supporting details.

- Understanding the details of accidents are important

- Discussing candidate mitigations with stakeholders provides good insight into mitigations 


\section{Stakeholders consulted during the Aircraft LOC Study}

- Regulatory agencies

- FAA

- NTSB

- Operators

- Air Line Pilots Association (ALPA)

- Commercial pilots

- Safety directors for Airlines
- Manufacturers

- Boeing

- Airbus

- Honeywell

- Other organizations

- CAST members

- NASA

- CALSPAN

- Flight Safety 


\section{Stakeholder feedback: Research Needs}

Envelope protection, envelope limiting and energy management (Avoid LOC). Stakeholders indicated that a high-priority mitigation toward preventing LOC is inhibiting an otherwise healthy aircraft from entering an unsafe condition.

1) Envelope protection: understand the benefits and identifying potential hazards

2) Envelope limiting:

3) Displays and automation for improved energy management

4) Automatic use of the propulsion system for envelope protection:

5) Partnerships to participate in verification and validation of these technologies. 


\section{Stakeholder feedback: Research Needs (Continued....)}

Improved automation for human factors Mitigation (Avoid LOC).

Stakeholders indicated that complexity of automatic systems, poor system architecture and a lack of human factors considerations in automatic systems are a key causal factor in aircraft loss of control. Potential mitigations include;

- 1) Reduced complexity in automation interfaces

- 2) Improved models of systems for increased pilot understanding

- 3) Improved feedback to the pilot about the state of automatic systems

- 4) Improved coordination between autopilot and autothrust systems

- 5) Automatic prevention of loss of control and pilot aids for recovery from a loss of control event.

- 6) Reduced "startle factor" for changes in automation ("bark before bite") 


\section{Stakeholder feedback: \\ Research Needs (Continued....)}

Training for upset recovery and prevention (Avoid, Detect, and Recover from LOC).

- Stakeholders are widely divided on the topic of training for loss of control recovery and prevention.

- Pilot unions and operators are at odds with regard to upset prevention and recovery training.

Key needs toward addressing LOC prevention and recovery training:

1) Research to develop training products for externally-induced loss of control (icing, wind shear, wake vortex, turbulence, heavy rain). 


\section{Stakeholder feedback: \\ Research Needs (Continued....)}

Key needs toward addressing LOC prevention and recovery training:

2) Identify the most effective way to train pilots to mitigate loss of control events:

a) Determine effective ways to utilize the URTA in training.

b) ID advantages and hazards with using motion-based and fixedbased simulations for training.

c) Perform research to understand where motion in simulation is most effective (seat cushion, gyroscopic devices, in-flight simulation, aerobatic training).

d) Prevention and recovery training: perform research that would give regulators, manufacturers, and operators guidance on the effective use of prevention training and the appropriate use of recovery training.

e) Research to determine when URT should be introduced to pilots during their career and how often to train for upset recovery to maintain proficiency. 


\section{Stakeholder feedback:}

\section{Research Needs (Continued....)}

Aerodynamic and dynamic model development for upset prevention and recovery (Recover).

- Stakeholders concerned about adequately modeling aircraft dynamics beyond the nominal flight envelope or in the presence of external influences such as wake vortex or icing.

- Inaccurate modeling may lead to negative training (AA587).

- key needs in the areas of aerodynamic and dynamic model development for upset prevention and recovery are:

1) Methods for accurate and cost-effective modeling outside the normal flight envelope

2) Development of generic models for upset prevention and recovery that include:

- Multiple configurations, Generic trends in models that can be used in training, Evaluate the effectiveness of generic models in training for specific aircraft types, Generic models that do not contribute to negative training

3) Research to determine control effectors most appropriate for loss of control recovery: Control effectiveness in unusual attitudes, Use of the propulsion system as an effector, Control allocation strategies. 


\section{Stakeholder feedback:}

Research Needs (Continued....)

Detection and notification of pending upset condition (Detect).

Stakeholders consistently emphasized the need to identify the development of a pending upset condition and provide the crew with sufficient information so they can take appropriate action to prevent an upset. Quite often the crew are caught off guard at the onset of an upset condition and have only seconds within which to identify the correct response. Incorrect responses may lead to an unrecoverable condition. Technologies are needed that:

1) Identify and warn of degraded energy states

2) Provide asymmetric thrust detection and notification

3) Identify and notify of spatial disorientation

4) Predict and mitigate PIO

5) Detect icing conditions and buildup and provide notification

6) Detect aircraft aerodynamic changes using real time system identification. 


\section{Causal factors}

Human Induced

- Manual handling errors

- Poor Energy Management

- Automation Effects On Human Induced Loss-Of-Control

- Spatial Disorientation

- Improper Procedures
Systems Induced

- Poor systems design

- Poor energy management

- Poor redundancy management

- Autopilot modes leading to loss of control

- Erroneous sensor data

- Pilot induced oscillation

- Loss of control power, authority, or effectiveness

- Display errors

- Propulsion system faults/ failures/damage

- Fire

\section{Externally Induced}

- Icing

- Turbulence

- Degrading Visibility

- Heavy Rain

- Low-Level Windshear 


\section{Human induced LOC: Manual Handling Errors}

\section{CF: Inadequate Pilot Training for Upset Prevention and}

Recovery: inappropriate or erroneous control inputs by the flight crew in response to abnormal events or flight regimes.

Mitigation: Improved upset recovery training

- Study the impact of upset recovery training during transitional flight training

- Study the effectiveness of providing pilots with an enhanced understanding of the behavior of an aircraft near or outside the limits of normal flight regimes.

- Manual control strategies during upset recovery

- Development of aerodynamics and dynamic models for out of envelope conditions (including generic models)

- Understanding the importance of simulator motion in upset recovery training.

- Evaluate the use of In-flight simulators for Upset Recovery Training. 


\section{Human induced LOC: Manual Handling Errors}

\section{CF: Atrophy Of Manual Flying Skills}

Mitigation: Provide pilots with increased opportunity to exercise manual flying skills.

- Assess how specific automated systems, both inside and outside the cockpit, are affecting the retention of manual flying skill.

- Develop guidelines for frequency of manual flight time for normal and abnormal operations in order to maintain pilot proficiency.

- Identify ways in which manual navigation, guidance, and control skills can be regularly practiced during normal flight operations in order to keep manual skills sharp.

\section{CF: Poor Aircraft Handling Qualities During Upset Events}

Mitigation: Develop automatic control mechanisms to prevent LOC, recover or aid in the recovery of the airplane

- Control aids for prevention and recovery from LOC . 


\section{Human induced LOC: Poor Energy Management}

CF: Poor Energy Management

Mitigation: Improve pilot awareness of energy state.

- Display and alerting methodologies for critical aircraft configuration states.

- Design criteria and methodologies for low energy alerting and warning systems.

- Improved envelope protection and envelope limiting systems to maintain energy state. 


\section{Human induced LOC:}

\section{Automation Effects On HI-LOC}

CF: Automation Confusion/Mode Confusion

-Pilot misunderstanding of automation

-Poor feedback to the pilot about the state of automation systems

- Lack of understanding of automation systems by the pilot -Failure of automation system

Mitigation: Develop more simple pilot interfaces to prevent confusion about automation.

- Human Centric Pilot interfaces.

- Human Centric Verification and Validation Methods .

- Develop Human Centric Models of Automatic Systems

- Procedures-plus-concepts training

- Research to determine most appropriate information to display to the pilot about the state of the automation 


\section{Systems Induced Loss of Control}

- Flight critical components are designed to have a failure rate of $10^{-9}$ per hour of operation

- System/Component failure is a trigger for LOC in;

- 1/3 of Part 121 LOC accidents

- $11 \%$ of Part 135 LOC accidents

- 8\% of Part 91 LOC accidents 


\section{Systems Induced Loss of Control Causal factors}

- Poor systems design

- Poor energy management

- Poor redundancy management

- Autopilot modes leading to loss of control

- Pilot induced oscillation (PIO)

- Air traffic operations

- Unstable approaches

- Aircraft system faults/failures/damage (non propulsion)

- Erroneous sensor data

- Loss of control power, authority, or effectiveness

- Automation and display errors

- Propulsion system faults/failures/damage

- Fire 


\section{Systems Induced LOC: \\ Faults, Failures and Damage}

Non fly-by-wire-aircraft (Commuter and GA)

Causal Factor: Poor energy management due to faults, failures or damage

Mitigation: Loss of control prevention and recovery systems for non-fly-by-wire aircraft:

- Participate in the development of automatic LOC prevention and recovery systems for non-fly-bywire aircraft

- Participate in the development of techniques and guidance for recovery from LOC for non-fly-bywire aircraft. 


\section{Other Systems related Mitigations and Research}

- System Safety analysis of NextGen operations

- Forensics and trend prediction

- Data mining FOQA, ASIAS and ASRS data for LOC trend information, causal factors and precursors to LOC 


\section{Environmentally Induced LOC}

- Not as significant of a factor as human induced LOC

\begin{tabular}{|l|c|c|c|}
\hline Causal Factor & $\begin{array}{l}\text { Part 121 and 135 } \\
\text { Scheduled } \\
\text { (40 LOC accidents) }\end{array}$ & $\begin{array}{l}\text { Part 135 } \\
\text { Unscheduled } \\
\text { (159 LOC accidents) }\end{array}$ & Part 91 \\
\hline Icing & $54 \%$ & $27 \%$ & $6 \%$ \\
\hline Turbulence & $11 \%$ & $22 \%$ & $20 \%$ \\
\hline Degrading Visibility & $9 \%$ & $14 \%$ & $18 \%$ \\
\hline Heavy Rain & $6 \%$ & $5 \%$ & $2 \%$ \\
\hline Low-Level Windshear & $4 \%$ & $3 \%$ & $2 \%$ \\
\hline
\end{tabular}




\section{Mitigation and Technical Challenges}

- Improved health monitoring of aircraft systems

- Improved modeling in adverse conditions such as out-ofenvelope flight

- Research to support loss of control training

- Maneuvering boundary identification and envelope limiting

- Pilot increased awareness about the health and state of the aircraft

- Integrated aerodynamics and propulsion control

- Automatic control system technology to provide good handling qualities

- Data mining for trend identification

- System Safety Analysis of NextGen operational impact

- Research to support improved verification and validation of complex systems. 


\section{Conclusions}

- Human induced LOC causal factors are a stronger contributor to LOC accidents when compared to Systems induced and Environmentally induced causal factors.

- Avoidance and detection mitigations should be higher priority than recovery based mitigations but......

- Recovery based mitigations are important for coverage of "breaking the chain" of events.

- Prevention and Recovery Training may have a nearer term impact than technology based solutions.

- New technologies and NextGen operations may introduce new and unforeseen LOC hazards.

- Hazard analysis is required

- Data mining of FOQA, NTRS and ASRS

- Verification and Validation methods need improvement to keep pace with NextGen complexities 